\title{
Seven Passive Greenhouse Synergies
}

\author{
Marius M. Balas
}

Aurel Vlaicu University, 77 B-dul Revoluţiei, 310130 Arad, Romania

e-mail: marius.balas@uav.ro

\begin{abstract}
This paper describes the effects of applying at a large scale a new agricultural system, based on passive greenhouses, from a system engineering perspective. Passive greenhouses use only the renewable energy sources: geothermal, wind and sun, by means of cool water heat pumps, wind turbines and photovoltaic panels. Thereby they are fully free of any energetic infrastructure and can be installed in remote areas, even in deserts. They offer a fundamental sustainable agricultural resource and a global ecological reconstruction opportunity. The surface needed by a greenhouse is much smaller compared to an equivalent conventional agriculture exploitation. The huge unshackled surfaces that result if using passive greenhouses may be reconverted into forests, pastures, orchards or pounds, thereby decreasing the carbon footprint. The main obstacle is the high investment cost, which can be minimized by optimizing the size of each energy source according to the user's specifications, the local climate, and by intelligent control algorithms. The equipment prices are constantly decreasing and the newly created market will generate jobs and give a boost to related industries. A holistic view of a the passive greenhouse farming system reveals a set of synergies that increase chances for future implementation.
\end{abstract}

Keywords: sustainable energy; passive greenhouse; heat pump; wind generator; photovoltaic panel; Watergy; carbon footprint; environment reconstruction; intelligent control

\section{Passive Greenhouses. The Renewable Energy Synergy}

Passive Greenhouse PG is the agricultural equivalent of the Passive House. Instead of hosting people, PGs are hosting plants. A passive house reduces its ecological footprint by minimizing heating/cooling energy requirements, using special construction solutions. At the same time, they use only renewable energy sources [1]. The most effective renewable energy source that supports the Passive House is geo-thermal, by means of the heat pumps. Heat pumps may be found in two constructive versions: either with cool water (closed or open circuits) or simply with air [2]. Other common renewable energy solutions are wind turbines, solar panels (photovoltaic or thermal) and biomass [3]. 
The same ideas are animating the PG concept, which is even more radical: a PG uses exclusively renewable energy sources and is totally independent of any energetic infrastructure: gas, electricity, hot water, etc. We coined the term PG for the first time in 2004 [4]. We continued to develop this subject by some other papers and book chapters and in 2010 a more comprehensive chapter issued at an open publishing house [5]. The 2010 chapter is briefly exposing the essence of our approach. The present work is mainly synthesizing the argumentation that stands behind the PG concept and underlines numerous synergies that encourage a great number of potential users to invest into PGs.

We can now point to the first synergy that opens the way for the others:

1) The renewable energy synergy: A PG can use in situ, with no grid conversion, all the significant renewable energy sources: geo-thermal, wind, solar and biomass

The first three energy sources are found in any passive building, yet biomass is an unavoidable byproduct of greenhouse technology. The fact that this by-product can be turned into energy and fertilizer in situ is an asset of greenhouse technology, not fully exploited now, but tested at 1:1 scale with very positive results [6] (see next section).

All the components incorporated in PGs have been produced for decades and have created their own markets. The specific technical constraints are well known and no particular risks should be expected. On the other side, only one major obstacle stands to be removed: the initial investment price. The real contribution of the PG concept and its potential effects over our energetic, agricultural and food systems is to reveal hidden resources and their beneficial consequences, from the system engineering perspective, and to show ways to minimize the investment costs.

\section{The Watergy Synergy}

A particularly important new concept issued by the greenhouse scientific research is the Watergy, an integrated approach for water treatment, building climate control and food production [7]. The Watergy concept is materialized by a closed greenhouse, a well-insulated greenhouse, provided with devices able to condense the water vapors. A closed greenhouse can re-circulate the initial amount of water, and even produce fresh water out of salt or grey waters [8]. A related domain is the Advanced Life Support, bringing together research aimed at the habitation of remote areas (desert and polar regions) or for long-term space journeys. The Watergy is a key opportunity for arid regions with low water resources: the Gulf region, Sahara, Central Asia, Australia, south-western USA, Mexico and some Mediterranean countries. Temperate and cold climate countries could also use some of the Watergy principles. 
Besides the specific water economy features of the closed greenhouse, any conventional greenhouse can be biased in accordance with the watergy principles, so we can point a second synergy:

2) The water synergy: $P G$ s need water at the same time, for the heat pumps and for the plants. Greenhouses are at the same time, water consumers and water recyclers

A consequence of this fact is that one can install PGs anywhere one can find or build fresh water reserves (rivers, lakes, natural or artificial aquifers, glaciers, rain, even sea salt water) or where water can be transported and stocked.

The most audacious approach in this issue is represented by Fiwihex closed greenhouse, involving a great artificial aquifer that stores warm water and is synergistically used as a bioreactor, able to produce biogas [6]. Fiwihex of Netherlands is specialized in high efficiency fine-wire heat exchangers, which in this case, may replace heat pumps, thanks to the natural stratification of the different temperature water layers favored by the great volume of the aquifer. The high heat capacities of the water and of the aquifer rocks enable the storage of great amounts of energy. It is proved that during a year, the greenhouse effect can produce, in a nonventilated closed greenhouse, more energy than is actually needed. The supplementary energy stored into the aquifer can sustainably support the Fiwihex closed greenhouse.

\section{The Passive Greenhouse Construction Synergy}

\subsection{The Passive Greenhouse System}

A standard PG aggregates three complementary energy sources:

A. A heat pump, extracting energy from cold phreatic water or another type of aquifer

The heat pump is the main PG energy source, in an implicit open circuit configuration, with at least two water wells (cold and warm).

3) The construction synergy: Drilling water wells for the heat pumps is synergetic with the watering of the plants

Geo-thermal energy is reliable and stable, and the related heat pumps can be used for heating, as well as, for cooling. However, heat pumps cannot work totally independently; they need $15-20 \%$ of their nominal power for re-circulating the water of the exterior circuit. Instead of connecting to the electric energy distribution network, PGs are provided with two secondary renewable energy sources: 


\section{B. A wind generator}

\section{A matrix of solar photovoltaic panels}

Wind and solar energy are extremely variable compared to geothermal, but complementary, so their aggregation is useful. With the help of a DC battery one can store the wind and the solar energy, supplying the heat pump and all the PG's electrical equipment needs. Besides charging the batteries, the solar panels may shade, at the same time, the plants, when solar radiation is excessive and the greenhouse effect would overheat the greenhouse. Because the secondary energy sources have to produce only a small part of the nominal power of the heat pump, their sizes and prices are correspondently low.

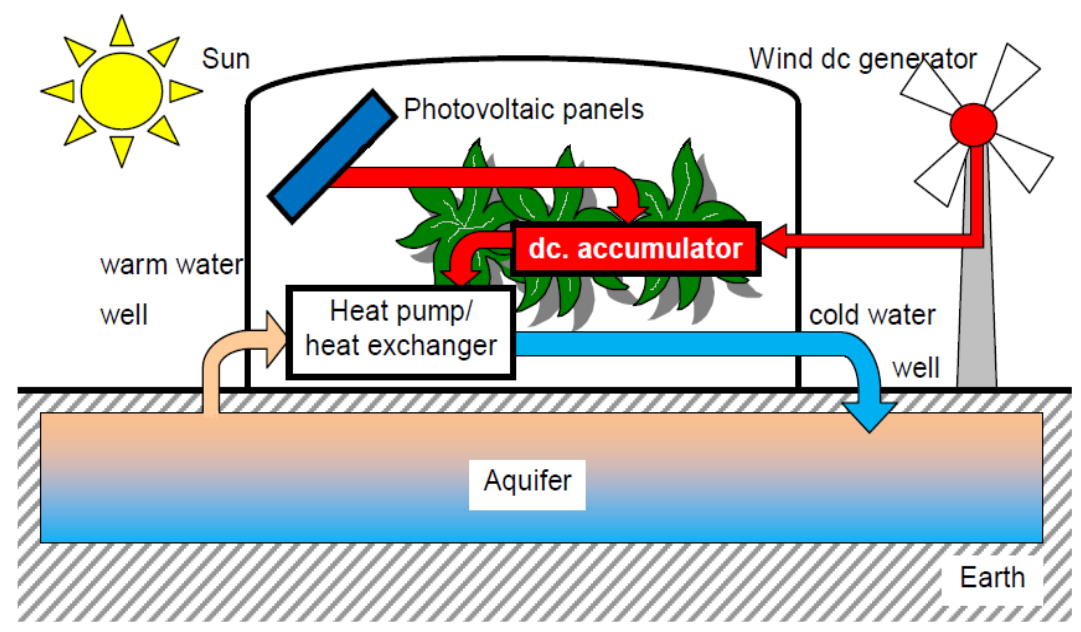

Figure 1

A generic Passive Greenhouse with aquifer

One of the first greenhouses equipped with a heat pump, working in parallel with a gas heat source, was mentioned in 2007 in one of the key works of the greenhouse theoretical domain [9]. Since then heat pumps are currently included in the offers of greenhouse producers. It is to remark that the first attempts to fit greenhouses with heat pumps were rather reserved, with tendency to oversize the heat pumps power output, which increase unnecessarily the investment costs.

PGs are proposing more than heat pumps connected to electricity or gas distribution networks, which means infrastructure investment costs. PG means a full independence of any energy or water utility infrastructure. This is cutting the umbilical cord that keeps greenhouses stuck to localities, and offers them an enormous development potential in remote areas.

It is to remark that PGs are directly using the energy, avoiding the costs associated with a grid connection, which charge the average renewable energy systems. 
While the Fiwihex closed greenhouse concept implies great built surfaces and huge artificial aquifers that are used also as bioreactors, which altogether increase the costs, the manual labor and the system's ecological impact, PGs propose a minimalist yet effective architecture, suited to any possible user, starting with the small family or hobby solar greenhouse up to the largest farms.

The main PG's disadvantage is its high initial investment cost. The optimal sizing of the energy sources and appropriate tunings for the PG control algorithms may be achieved only under computer assistance and expert guidance.

\subsection{The Computer Modeling of the Passive Greenhouse}

Many greenhouses with heat pumps were built recently, in different countries, Romania included. The weights of heat pumps in their energy balance are different. The experience of the greenhouse builders is growing in this matter, and a large amount of specific knowledge about greenhouse construction and interaction with the environment is now being accumulated. The ultimate realization of this knowledge will be achieved when we can embed it into computers. Most of our previous PG studies used computer models that we began to develop since 2004, starting from the experimental data issued from the Experimental Greenhouse of the Southern University of Toulon-Var, France. When such a model originates out of experimental data, its validation is not a problem and its confidence degree is sufficiently high, allowing us to assume results of simulations following a large variety of scenarios. The models' parameters are tuned and optimized for the most significant operating points. After that, the models are able to interpolate the evolution of the greenhouses' variables when fed with new input data. The input data may consist of technical specifications for various types of equipment, including investment and exploitation costs, they may reproduce the behavior of the greenhouse under extreme climate conditions, etc.

Two main strategies were applied for the identification of the Toulon Greenhouse:

- The synthetic approach, consisting of identifying the models of the significant operating points by neural networks and aggregating the resulting models by a fuzzy fusion procedure [10]

- The structural approach, consisting of identifying the models of the significant operating points by structural models (differential equations of the main physical phenomena) and tuning the physical parameters of the models with genetic algorithms [11], neural networks or other optimization methods (see Fig. 2) [12]

Our own choice continues to be the structural ISO (input-state-output) deterministic model, like the one in Fig. 3, able to clearly and distinctly estimate the evolution of the state and output variables (inside temperature, ventilation, air and soil humidity, $\mathrm{CO}_{2}$ concentration, etc.), under the influence of the input variables (external temperature, solar radiation, humidity, wind, heating/cooling power, etc.) 

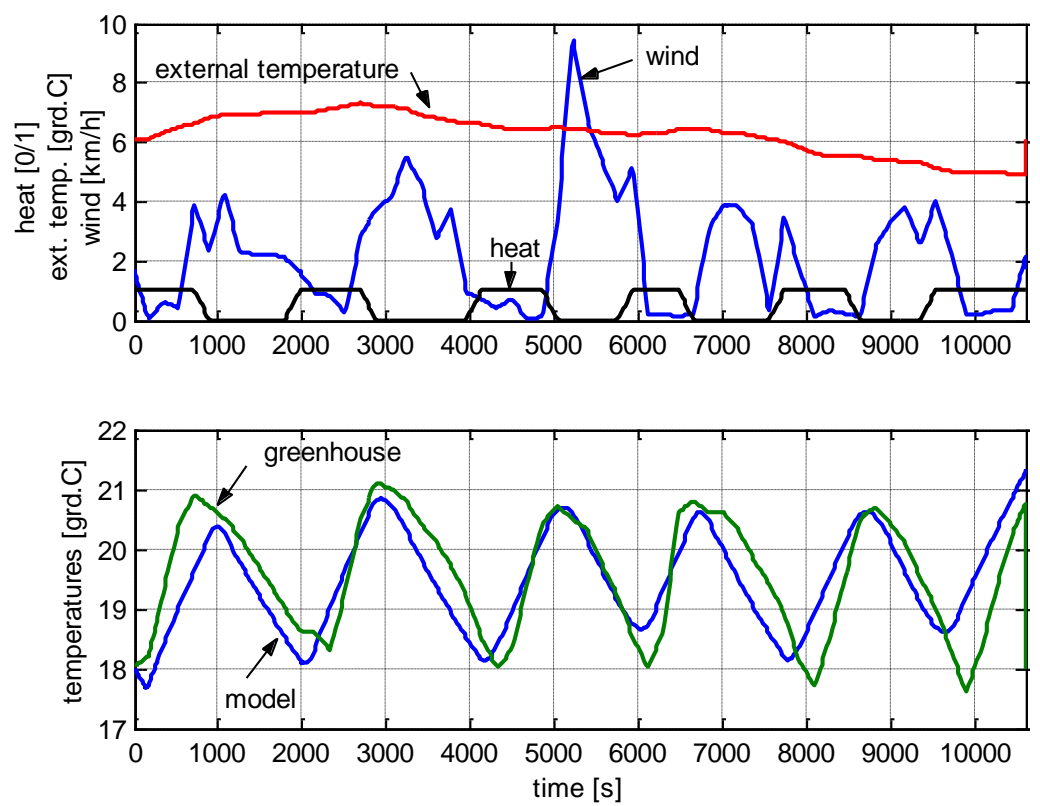

Figure 2

The identification of the greenhouse model starting from experimental data

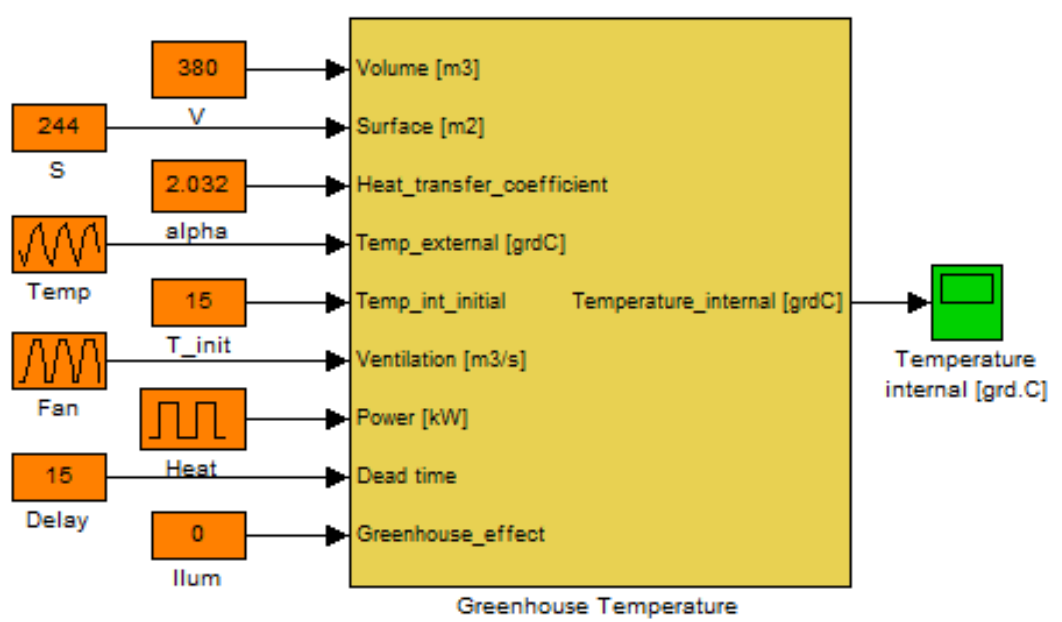

Figure 3

A Matlab implementation of the structural greenhouse model, for the inside temperature 


\subsection{The Passive Greenhouse Control}

The PG automated control is necessarily depending of its construction. Greenhouses are highly nonlinear and variable. Many quantities must be taken into consideration, which is not a trivial task. Some of them are extremely uncertain, like for instance the estimation of the crop development, which is needed for a correct feeding of the plants with nutrients and water. In the PG case, a supplementary difficulty occurs: the high inertia of the heat pump, which is not able to change its power as fast as a gas burner device, for example. On the other hand, the precision asked when controlling all the greenhouse parameters is sufficiently weak. In other words, greenhouses are rather tolerant. This suggests the PG system as a perfectly compliant system with the application of intelligent control algorithms.

The usual greenhouse control equipment belongs to the PLC family, and in recent years, all the facilities demanded by remote PLC operation and networking became fully accessible.

Two strategies are bounding the greenhouse control algorithms field:

a) The Optimal Control [9], extremely precise and sharp, which is well suited for standardized greenhouses (namely Venlo)

b) The Expert Control [5] under its different versions, including the fuzzy-expert control, which is suboptimal, yet extremely robust, adaptive and flexible. The expert systems are able to embed heuristic solutions and can cope with the specific knowledge and specifications of each particular user

\section{The Carbon and the Trophic Synergies}

The property of the above generic PG, that is ensuring its individuality, is its total independence of any infrastructure, except transportation. That is why PGs may be associated in some points with the class of the Portable Greenhouses.

All the monitoring and automated control demanded by PGs may be executed by means of the Internet, or by any other telecommunication systems so human presence is necessary only during farming activity. As a matter of fact, even the human presence will be eventually made unnecessary, when applying another powerful concept that is emerging these days: the Autonomous Greenhouse.

This feature makes possible a new global agricultural system that has the potential to boost the performances of our food system and the quality of our natural environment, at a planetary scale. The previous papers containing the argumentation that supports the concept of the PG Agricultural System are recalled in [5] and detailed in its bibliographic references. In the following sections, we will provide a review of this matter. 


\subsection{The Passive Greenhouse Control}

The carbon footprint is the total set of greenhouse gas GHG emissions, like $\mathrm{CO}_{2}$, caused by a certain process. Our civilization produces a huge carbon footprint because of two specific activities:

- Extremely rapid burning of the fossil fuels accumulated during million years. The oxidations are extracting the atmospheric oxygen and replacing it with $\mathrm{CO}_{2}$ and other chemical compounds

- Deforestation. Because of their great size compared to other plants, trees are able to compensate for the growth of $\mathrm{CO}_{2}$ atmospheric concentration. Their metabolism demands great quantities of $\mathrm{CO}_{2}$ and the release of oxygen $\mathrm{O}_{2}$. The continuous reduction of the forest enhances our carbon footprint.

The processes that reduce the $\mathrm{CO}_{2}$ concentration are known as carbon offsets. The most rightful carbon offset strategy would be the reforestation. Trees are storing carbon through photosynthesis, converting $\mathrm{CO}_{2}$ and water into oxygen and plant matter. However, reforestation is expensive and long lasting.

As one can observe in the literature, the daily $\mathrm{CO}_{2}$ consumption in greenhouses is very high (100-250 kg/ha), similar to a forest, due to the high density of the plants and to the ideal growing conditions.

Increasing the surface occupied by $\mathrm{PGs}$ is therefore more or less equivalent to reforestation. Besides their own carbon offset, greenhouses are also generating a collateral carbon offset, due to the consequential ecological reconstruction.

\subsection{The Ecological Reconstruction}

A land surface occupied by PGs produces a certain carbon offset but its surface is ecologically depreciated. However, the extensive use of PGs offers us the opportunity to reconsider the global structure of the agricultural lands and to reconstruct huge surfaces, in the proximity of our towns and villages. The price to be paid is to sacrifice some remote areas, where the PG farms are installed.

The following assumptions support this idea:

- Using the same surface area, greenhouses can feed at least 5-10 times more people than cereal cultivated lands;

- Sacrificing certain remote or inappropriate zones, for conventional agriculture in the favor of the PG farms, is feasible

- Replacing the cereal cultures with greenhouses, frees huge land surfaces

- The unshackled surfaces that result, may be converted into forests, pastures, orchards, pounds, etc. 
We can formulate now a fourth synergy:

4) The carbon offset synergy: Besides its own carbon offset effect, extending the PG surfaces creates a supplementary carbon offset thanks to the consequent ecological reconstruction of the newly liberated surfaces

\subsection{The Passive Greenhouses and the Trophic Chains}

Feeding the human population can be accomplished by two food chains, supported by the capacity of the plants to produce vegetal matter by photosynthesis:

a) A three trophic levels chain: plants $\rightarrow$ animals $\rightarrow$ humans

b) A two trophic levels chain: plants $\rightarrow$ humans

A lot of energy is lost at each transfer from a trophic level to another. That is why the food chain a) needs much more agricultural surfaces than the food chain $\mathbf{b}$. By the help of the greenhouses we can further reduce the surface demanded by the food chain b). However we fail to imagine a totally vegetarian population and we must find sustainable solutions to keep food chain a). The ecological reconstruction can sustain a new type of zootechny, that lets the common species of animals that are now fed with cereals (cattle, pigs, birds, etc.) to live in a natural way, like sheep for instance. The animals' quality will significantly improve in all senses, and their carbon footprint will decrease. We may think about cattle for instance: avoiding feeding them with corn and letting them out of the stables to pasture is perfectly suited to their nature and it will obviously decrease the DHG emissions.

We find here a fifth synergy:

5) The trophic synergy: The $P G$ agricultural system is directly reinforcing the two trophic levels chain and in the same time is increasing the quality of the three trophic levels chain

Besides economical or technological advantages, a greenhouse based food system reduces the production uncertainties, the risks of bad weather and climate changes, pests, diseases, etc.

\section{The Economic Synergies}

Renewable energy sources are expensive. PGs are usually provided with three items, a heat pump, a wind turbine and solar panels. It is natural for an investor to ask for accurate investment analysis and business plans. The only way to make feasible such a structure is its size optimization associated with a smart control, in order to avoid over-sizing and energy or crop waste. 
Each of the necessary energy sources has created and established its own market. The designer's task is just the correct choice of products. The nominal power of each component and the construction parameters of the greenhouse must be carefully balanced, taking into account the climatic features of the location and the exploitation characteristics, which may differ according to each user's specifications.

Our main tool is the computer modeling. Besides handling of the internal temperature, which is the key factor, the simulations can assist us in any particular optimization problem, as for instance the minimization of the investment costs.

A recent investment analysis performed by a Romanian company for the 2012 Romanian market, reveals the following encouraging facts, which prove the feasibility of the PG concept:

- The necessary equipment for building different PG configurations is available and a related market of builders that have experienced greenhouses provided with heat pumps is functioning

- Many greenhouse farmers have already successfully experienced heat pump greenhouses

- The evolution of the prices is favorable for all components

- A representative price of a fully equipped $1000 \mathrm{~m}^{2} \mathrm{PG}$ is about 285,000 RON $(62,400$ EURO) comparied to 220,000 RON (48,200 EURO) for the same greenhouse provided with gas burners (when growing tomatoes); the infrastructure prices (gas network connection) is not taken into account

- The estimated payback period is approximately seven years

The renewable energy market is now oriented towards passive houses. In great lines passive houses and PGs are sharing the same technological platform. If the PGs will create a new market, this will boost the whole renewable energy market (higher trade turnovers, lower prices, more jobs, etc.), with beneficial effects over the economies of the countries involved into the PG agricultural system development.

Therefore we can point the sixth synergy:

6) The economical synergy: PGs are already feasible and use available technologies and homologated components, which are creating a fast growing market; they have the potential to boost the renewable energy market and to generate a sustainable economic growth 


\section{The Political Synergy}

A last, but perhaps the most important of the synergies, is related to some of the fundamental objectives of our society:

7) The political synergy: $P G s$ are appeasing some political goals that seemed contradictory so far: economical growing and efficiency, increasing the number of jobs, reducing the carbon footprint and increasing the carbon offset, improving the quality of life by a structural ecological reconstruction of our environment and removing many of the agricultural and alimentation risks

\section{Conclusions}

The Passive Greenhouses main assets are 100\% free renewable energy and the quality of being deployable virtually anywhere one can find or construct aquifers. A global Passive Greenhouses agricultural system is made possible by a chain of synergies that support its feasibility. We outlined seven synergies: the renewable energy, the water, the construction, the carbon offset, the trophic, the economical and the political synergies.

Such an agricultural system gives us the chance to repurpose a great deal of the existing agricultural terrain and to ecologically reconstruct our environment in a more efficient and ecologic way.

This approach relies exclusively on existing renewable energy sources and has no significant technological risks or ecological impacts.

The main obstacle to be removed in Passive Greenhouses is the high investment cost, which can be partially addressed by carefully optimizing the construction and the energy sources design, and using intelligent control algorithms.

\section{References}

[1] Gröndahl M., Gates G.: The Secrets of a Passive House, New York Times website, September 25, 2010, Retrieved October 4, 2012

[2] Heat Pump Statistics - Outlook 2012, European Heat Pump Association website, Retrieved October 4, 2012

[3] Renewable Energy Manual, Iowa Energy Center website. Retrieved Oct. 4, 2012

[4] Balas M. M., Cociuba N., Musca C.: The Energetic Passive Greenhouses, Analele Universităţii Aurel Vlaicu din Arad, Arad, 2004, pp. 524-529

[5] Balas M. M., Musca C., Musca S. V., The Passive Greenhouses, in Paths to Sustainable Energy, Editors: Nathwani J. J. and Ng, A. InTech, Dec. 30, 2010, pp. 75-92 
[6] Nederhoff E. Closed Greenhouses and Heat Producing Greenhouses, The Grower, New Zealand, No. 61, 2006, pp. 67-69

[7] Watergy. Water and Energy Efficiency, Energy Efficiency Global Forum, Orlando, USA, March 27-29, 2012. http://www.watergy.org/ Retrieved Oct. 8,2012

[8] van Straten G.: Investment in Novel Closed Greenhouse Systems: the Watery design and other developments, First Workshop on Investment in Protected Cultivation in GCC Countries, Abu Dhabi, 2006

[9] van Ooteghem R. J. C.: Optimal Control Design for a Solar Greenhouse, Ph.D. thesis, Wageningen University, 2007. Wageningen UR site (Wageningen Dissertations). Retrieved Oct. 9, 2012

[10] Pessel N., Duplaix J., Balmat J. F., Lafont F.: A Multi-Structure Modeling Methodology, in Soft Computing-based Modeling in Intelligent Systems and Technologies, edited by Balas V., Fodor J. and Várkonyi-Kóczy A., Springer, 2009, Vol. 196, pp. 93-114

[11] Balas M. M., Duplaix J., Bouchouicha M., Balas S. V.: Modeling the Wind's Influence over the Heat Flow of the Greenhouses, Journal of Intelligent \& Fuzzy Systems, 2008, Vol. 19, No. 1, pp. 29-40

[12] Balas M. M., Musca C., Musca S. V., The Passive Greenhouses, in Paths to Sustainable Energy, edited by Nathwani J. J. and Ng, A., InTechOpen, 30 Dec., 2010, pp. 75-92 